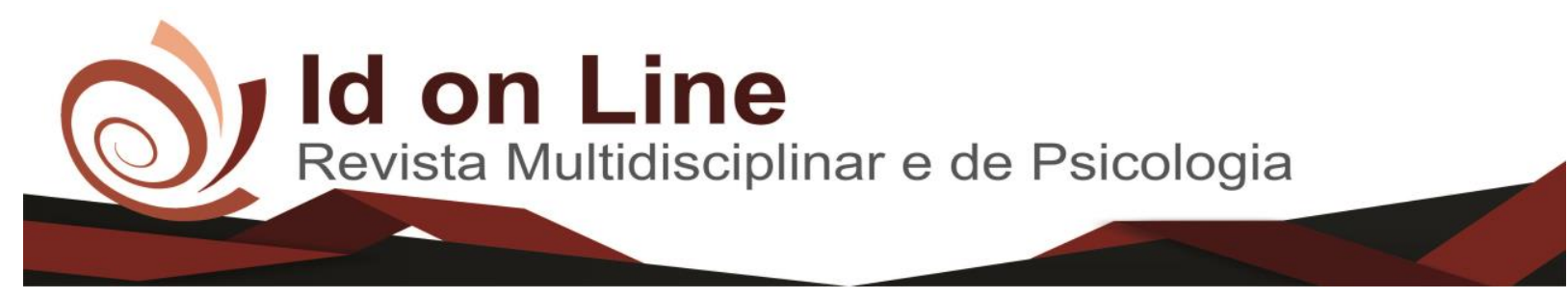

Artigo de Revisão

\title{
O Lúdico como Ferramenta no Ensino da Matemática
}

Luciana Verêda da Silva ${ }^{l}$; Clenilson Panta Angelim ${ }^{2}$

Resumo: O presente trabalho foi desenvolvido com base em pesquisas bibliográficas, exploratórias, teóricas e qualitativas e tem como principal objetivo fazer uma análise e reflexão sobre a importância de se trabalhar com o lúdico no ensino de matemática, enfatizando principalmente as contribuições encontradas nesse processo, reforçando que o lúdico pode e deve ser uma ferramenta positiva no ensino da matemática, apresentando a importância de se trabalhar com atividades lúdicas no ensino, ressaltando suas contribuições nas aulas de matemática, tanto para o professor quanto para a criança, principalmente nos primeiros anos do ensino (infantil e fundamental I), sabendo que o lúdico beneficiará de maneira significativa para o desenvolvimento intelectual e potencial de cada criança. Apresentar ainda que através do lúdico inserido no ensino de matemática, irá trazer um resultado positivo com relação ao aprendizado das crianças, pelo brincar. Conceituar o termo Lúdico como sendo qualidade daquilo que estimula através da fantasia, do divertimento ou da brincadeira, na visão de alguns autores reforçar esses conceitos percebendo o quanto o ato de brincar é importante para o desenvolvimento intelectual e cognitivo dos estudantes ainda crianças, mas ainda citar alguns jogos que auxiliam no processo de alfabetização matemática, bem como suas contribuições nessa área do conhecimento matemático.

Palavras chaves: Lúdico, Aprendizagem matemática, e Educação matemática.

\section{The Ludic as a Tool in Mathematics Teaching}

\begin{abstract}
The present work was developed based on bibliographical, exploratory, theoretical and qualitative researches and has as main objective to make an analysis and reflection on the importance of working with the lúdico in the teaching of mathematics, emphasizing mainly the contributions found in this process, reinforcing that the playfulness can and should be a positive tool in teaching mathematics, presenting the importance of working with play activities in teaching, emphasizing their contributions in mathematics classes, both for the teacher and for the child, especially in the first years of teaching ( child and fundamental I), knowing that the playful will benefit significantly to the intellectual and potential development of each child. To show that through the playful inserted in the teaching of mathematics, will bring a positive result regarding the learning of the children, by playing. To conceptualize the term play as the quality of what stimulates through fantasy, fun or play, in the view of some authors to reinforce these concepts perceiving how much the act of playing is important for the intellectual and cognitive development of students still children, but still to mention some games that aid in the process of mathematical literacy, as well as their contributions in this area of mathematical knowledge.
\end{abstract}

Keywords: Playful, Mathematical Learning, and Mathematical Education.

\footnotetext{
1 Graduanda do curso de Licenciatura plena em matemática, Faculdade de Ciências Humanas do Sertão Central-Fachusc, E-mail: lucianavereda@hotmail.com

2 Professor do curso de Licenciatura plena em matemática, Faculdade de Ciências Humanas do Sertão Central-Fachusc,

E-mail: clenilson2005@yahoo.com.br
} 


\section{Introdução}

Durante muito tempo a matemática foi transmitida de forma que os alunos passaram a ficar apreensivos, com receio da disciplina, e ainda hoje é visível este desânimo pela matemática por parte dos estudantes.

O que levou a analisar o tema "O lúdico como ferramenta no ensino da matemática", foi pelo fato de querer reforçar ainda mais a importância de se trabalhar com atividades lúdicas no ensino de matemática, ressaltando suas contribuições tanto para o professor quanto para a criança. Hoje o educador pode e deve utilizar o lúdico nas diferentes situações dentro da sala durante suas aulas de matemática, porém nem sempre vemos educadores que estão dispostos a mudar sua metodologia, deixando de lado um método tradicional para seguir uma postura lúdica, incluindo os jogos e brincadeiras em suas aulas, mesmo sabendo que o jogo no ensino de matemática pode ser utilizado como um instrumento norteador que facilita o processo de ensino e aprendizagem do aluno na disciplina em questão. O lúdico beneficiará de maneira positiva para o desenvolvimento intelectual e potencial de cada criança, onde compete ao professor intervir de forma adequada sem interferir na criatividade dela.

Segundo Zatz Halaban (2006); brincar é essencial para a criança, pois é deste modo que ela descobre o mundo à sua volta e aprende a interagir com ele. O lúdico está sempre presente, o que quer que a criança esteja fazendo. Dessa forma o ensino de matemática tem sua importância na vida do educando, e bem antes de sua entrada nas instituições a criança já está em contato com a matemática, pelo simples fato de que ela está presente em muitas situações em nosso cotidiano. Dantas, Rais, Juy (2012, p. 08) reforça que:

\footnotetext{
A criança já traz para a escola alguns "conceitos" numéricos que ela já estabelece singularidade, pois são usados em seu dia a dia, como por exemplo, o número da sua casa e que cabe a escola o papel de incentivar a criança para que ela se aproprie do sistema de numeração de forma prazerosa e satisfatória. A criança precisa ter noção de sequência numérica para poder utilizar. (DANTAS, RAIS, JUY 2012, p. 08).
}

Mas ao ingressar numa instituição os estudantes começam a conhecer uma matemática que para eles não tem significado, cheia de regras e fórmulas, bem como fora do seu contexto social, os mesmos começam a ter uma visão diferente sobre o ensino da matemática, dizendo ser uma disciplina difícil, e acabam por se sentirem incapazes e impossibilitados de aprenderem, o que lhe é transmitido pela forma como lhe é transmitida. 
O presente trabalho pretende mostrar que através do lúdico inserido no ensino de matemática, principalmente nas séries iniciais, poderá ter um resultado positivo com relação ao aprendizado das crianças, pelo brincar. Brincadeira essa com o intuito de melhorar o raciocínio lógico da criança de forma divertida e criativa, e amadurecer esse pensamento na mente do educando que esse brincar não é pra passar o tempo, como reforça Kishimoto (1998) quando diz que "o jogo não pode ser visto apenas como divertimento ou brincadeira para gastar energia, pois ele favorece o desenvolvimento físico, cognitivo, afetivo, social e moral. Fazer com que o aluno descubra e entenda que a matemática pode ir além dos cálculos e das fórmulas, aderindo uma forma também prazerosa ao ato de ensinar e que pode ser sentido pelos estudantes ao perceberem essa prática sendo repassada pelo professor. De acordo com Cunha, "O Brincar desenvolve as habilidades da criança de forma natural, pois brincando aprende a socializar-se com outras crianças, desenvolve a motricidade, a mente, a criatividade, sem cobrança ou medo, mas sim com prazer" (CUNHA, 2001, p.14).

O lúdico é a brincadeira, o entretenimento das pessoas envolvidas, o jogo, a diversão. É pelo brincar e através dele que o estudante se desenvolve e é sob esse pensamento que será desenvolvido esse trabalho, para que o aprendizado de matemática se torne ainda mais atrativo, divertido e que desperte o interesse das pessoas envolvidas, professores/alunos.

Conforme Corbalán, apud Alsina,

\begin{abstract}
Ensinar e aprender matemática pode e deve ser uma experiência com bom êxito do sentido de algo que traz felicidade aos alunos. Curiosamente quase nunca se cita a felicidade dentro dos objetivos a serem alcançados no processo ensino-aprendizagem, é evidente que só poderemos falar de um trabalho docente bem feito quando todos alcançarmos um grau de felicidade satisfatório. (CORBALÁN, apud ALSINA, 1994, p. 14).
\end{abstract}

Essa satisfação deve ser de ambas as partes não terão aprendizado se somente o professor demonstrar interesse, o professor deverá buscar estratégias que chame a atenção do estudante para que ele sinta-se atraído pelo que está sendo visto, e que encontre significado naquilo que está sendo repassado pelo educador.

Com base em pesquisas em sites e estudos em trabalhos relacionados ao tema, o presente trabalho está organizado em subtítulos que apresentarão desde a definição do termo Lúdico, se referindo a brincadeiras, a momentos de diversão, onde estão incluídos os jogos, brinquedos e, brincadeiras, por ser um aliado e está auxiliando nas aulas de matemática, tornando-as mais agradáveis e prazerosas, tanto para o aluno, como para o professor. Mais adiante, sobre a importância do lúdico no ensino de matemática, principalmente nas series iniciais, destacando 
as contribuições no auxilio das aulas de matemática bem como distanciar dos estudantes o bloqueio que sentem pela disciplina e que se consideram incapazes de aprendê-la. Logo após, falar sobre as contribuições dos jogos no processo de alfabetização matemática, buscando estratégias que facilitem nesse processo e que consigam com que seus alunos permaneçam concentrados em suas aulas, sem que fiquem estressados, cansados e reconheçam as aulas como atrativas e o professor demonstre ainda mais motivação naquilo cujo qual está exercendo.

\section{Metodologia}

Como método para a realização deste trabalho, foi realizado pesquisas: exploratória, com o objetivo de transmitir uma boa compreensão e precisão sobre o tema abordado, teórica, pois foi necessário ter um embasamento acerca do pensamento de alguns autores, para que pudesse explicar melhor o assunto levantado e qualitativa, pois um assunto de grande relevância precisa ser aprofundado para que se tenha um entendimento das pessoas envolvidas, professor/aluno.

Foram feitos estudos em trabalhos como: artigos, tccs, teses, monografias entre outros, dos quais tratavam de assuntos que tinham relação com o lúdico como ferramenta no ensino de matemática. E a partir desses trabalhos foi feito uma pesquisa bibliográfica para obtenção de dados importantes que pudessem enriquecer este trabalho, por meio de pensamentos de alguns autores que defendiam e consideravam o assunto importante.

Para facilitar a pesquisa foram usadas palavras chaves como: o lúdico no ensino de matemática, a importância do lúdico no processo ensino aprendizagem da matemática, lúdico como instrumento no ensino, a importância dos jogos na educação matemática.

\section{O Lúdico}

Qualidade daquilo que estimula através da fantasia, do divertimento ou da brincadeira. Trata-se de um conceito bastante utilizado na educação, principalmente a partir da criação da idéia de "jardim de infância", por Friedrich Froebel, que defendia o uso pedagógico de jogos e brinquedos, que deviam ser organizados e sutilmente dirigidos pelo professor. Mais tarde, 
vários educadores, como Piaget e Montessori, alertaram para a importância do lúdico na educação.

Segundo Vygotsky, por exemplo, o lúdico influencia muito o desenvolvimento da criança, pois é através do jogo que a criança aprende a agir, tem a curiosidade estimulada, adquire iniciativa e autoconfiança, além de proporcionar o desenvolvimento da linguagem, do pensamento e da concentração.

O lúdico também se origina na capacidade simbólica, na qual as imagens são consideradas fundamentais para instrumentalizar a criança, visando a construção do conhecimento e sua socialização.

Hoje, existe um consenso de que o lúdico é fator determinante na aprendizagem da criança. $\mathrm{O}$ ensino utilizando meios lúdicos criaria ambiente gratificantes e atraentes servindo como estímulo para o desenvolvimento integral da criança. Por isso, no âmbito do universo lúdico, foram criadas as brinquedotecas, os jogos educativos, os brinquedos pedagógicos e outros materiais. (EDUCA BRASIL, 2017).

De acordo com o pensamento de Santos (2001:37): “O comportamento lúdico não é um comportamento herdado, ele á adquirido pelas influências que recebemos no decorrer da evolução dos processos de desenvolvimento e aprendizagem". E essa construção pode ser feita pelo professor em suas aulas, enxergando as atividades lúdicas como um componente importante para a vida dos seres humanos, em especial as crianças, proporcionando momentos de prazer, diversão e aprendizado.

Santos (2001:35) afirma ainda que: “Assim sendo, o lúdico deve ser constante na vida dos seres humanos, desde o início de suas vidas até a velhice". Por desenvolver-se com maior facilidade ao brincar.

Segundo Almeida "o lúdico passou a ser reconhecido como traço essencial de Psicofisiologia do comportamento humano, (estudo das relações entre fenômenos psíquicos e fisiológicos). E que as implicações da necessidade lúdica extrapolaram as demarcações do brincar espontâneo". Desta forma ao ser inserido no ambiente escolar como parte do processo ensino aprendizagem esse termo deixa de ser relacionado apenas só ao brincar por diversão e passa tempo, e começa a ser um contribuinte nesse processo dando mais ânimo aos estudantes, principalmente nas séries iniciais, visando a disciplina de matemática, que ainda é vista como uma disciplina difícil, com cálculos e fórmulas, mas que pode ser mudado esse entendimento com relação ao ensino de matemática, e cabe também ao educador mudar essa idéia na mente de seus educandos, buscando novas formas de ensinar a matemática, mudando sua prática, 
buscando outros caminhos que possam favorecer nesse aprendizado. Mostrar que o brincar pode ser um meio importante e que por ele também há aprendizado, quando se trata de um brincar com responsabilidade e com um único objetivo, o de educar.

Volpato afirma que,

\begin{abstract}
O brincar na escola não pode - nem deve - ser o mesmo que brincar em casa, não se tratando do recreio, pois, o brincar na escola se define numa formação responsável pela socialização e aprendizagem da criança. No entanto maioria dos professores sente dificuldade em conciliar o jogo e a brincadeira em sala de aula, sendo às vezes negados pelo fato de pensarem que vai provocar indisciplina. Várias vezes, o lúdico é confundido com material concreto para ensinar matemática, como jogo da memória, dados, bingos de diversos tipos, entre outros. Nessa modalidade a atividade corre risco de não ser utilizada como mediadora de aprendizagens significativas para a criança, pois deve ser uma forma prazerosa de desenvolvimento visando a aprendizagem". (Volpato, 2002, p.97)
\end{abstract}

O conceito lúdico é usado por muitos educadores, por ser um grande aliado auxiliando em suas aulas, tornando assim mais agradáveis e prazerosas, tanto para o aluno, como para o professor, pois com esse pensamento lúdico, pretende-se melhorar a auto estima, o aprendizado, o interesse pela as aulas, o raciocínio e uma vontade de aprender matemática de uma forma diferente, porém divertida.

\title{
A importância do lúdico no ensino de matemática nas séries iniciais
}

De acordo com o PCN, 2001, p.26, "A matemática surgiu na antiguidade por necessidades da vida cotidiana, converteu-se em um imenso sistema de variadas e extensas disciplinas, como as demais ciências, reflete as leis sociais e serve de poderoso instrumento para o conhecimento do mundo e domínio da natureza". (PCN, 2001, p.26). E pela necessidade o homem da época, sem possuir ainda uma formalização de conceitos matemáticos e numéricos, precisou contar, medir, calcular. E com o passar do tempo foi aprimorada através dos estudos e se tornando uma disciplina/uma ciência com características próprias.

É uma disciplina considerada por muitos estudantes como difícil, complexa, simplesmente por estarem relacionando somente as fórmulas e cálculos e acabam sentindo dificuldades para assimilarem os conteúdos quando não demonstram interesses, por não compreenderem, por não fazerem relação com seu cotidiano, e não percebem que bem antes de sua entrada nas instituições a matemática já faz de alguma forma, parte de sua vida. 
Logo na infância a criança inicia sua vida estudantil, e a parti daí começa o processo de alfabetização, e todas as disciplinas que fazem parte desse processo, inclusive a matemática que deve ser transmitida de forma bem elaborada para que futuramente os estudantes não venham a ter maiores dificuldades. Com isso surge a ideia de inserir o lúdico no ensino de matemática, trabalhar dando ênfase nas atividades através do brincar, principalmente no ensino fundamental nos anos iniciais.

Em Vygotsky, percebemos que o ato de brincar é importante, pois possibilita ao indivíduo atuar em um nível cognitivo superior ao seu e isso impulsiona o desenvolvimento, além disso, o observador precisa estar preparado para distinguir nas atitudes das crianças, ações ou procedimentos que demonstrem os sinais dos critérios necessários para uma boa formação cognitiva, e até afetivo-social do aluno. A criança brinca pela necessidade de agir em relação ao mundo mais amplo dos adultos e não apenas ao universo dos objetos a que ela tem acesso (REGO, 2000, p. 82).

As crianças demonstram prazer em aprender, agir, e enfrentar os desafios seguros e confiantes, quando aprendem através de atividades lúdicas, elas produzem conhecimentos, nas experiências que são capazes de proporcionar o envolvimento do individuo que brinca. Por isso, é de fundamental importância que o professor utilize os jogos na sala de aula, estimulando os alunos para o desenvolvimento dos conteúdos propostos. Uma vez que o "objetivo dos professores de matemática deverá ser o de ajudar as pessoas a entender a matemática e encorajálas a acreditar que é natural e agradável continuar a usar e aprender matemática como uma parte sensível, natural e agradável”, diz (BRITO 2001, P. 43).

Segundo Borin (1996),

\begin{abstract}
Outro motivo para a introdução de jogos nas aulas de matemática é a possibilidade de diminuir bloqueios apresentados por muitos de nossos alunos que temem a matemática e sentem-se incapacitados para aprendê-la. Dentro da situação de jogo, onde é impossível uma atitude passiva, e a motivação é grande, notamos que, ao mesmo tempo em que esses alunos falam matemática, apresentam também um melhor desempenho e atitudes mais positivas frente a seus processos de aprendizagem. (BORIN,1996,9)
\end{abstract}

Os jogos é um recurso pedagógico eficaz se forem bem articulados e planejados pelo professor, contribuindo assim para a construção do conhecimento matemático da criança.

As frustrações e os pensamentos negativos com relação ao ensino de matemática deixarão de existir quando for colocado em prática o pensamento de que é de grande 
importância unir aos conceitos matemáticos, o lúdico, o brincar através dos jogos, deixando claro aos estudantes que estudar matemática também pode ser divertido, pode ser prazeroso.

\title{
A contribuição dos jogos no processo de alfabetização matemática
}

Kishimoto, p:106, afirma que " a introdução dos jogos na escola primária não é bem vista", isso acontece por que muitos educadores ainda estão presos e preocupados em não poder fugir daquilo que tem que ser trabalhado em sala com seus estudantes, cumprir com uma grade curricular e que mais tarde será cobrado, porém isso não pode nem deve ser um empecilho, o professor pode trabalhar qualquer que seja o conteúdo com auxilio da ludicidade, inserindo os jogos em suas aulas dando mais prazer aos seus estudantes que demonstram desinteresse pelas aulas de matemática por não apresentarem nenhuma novidade.

Segue uma afirmação de Friedmann, 1996:15,

\begin{abstract}
"Na escola "não dá tempo para brincar", justificam os educadores. Por quê? Há evidentemente um programa de ensino a ser cumprido e, objetivos a serem atingidos, para cada faixa etária. Com isso, o jogo fica relegado ao pátio destinado a preencher intervalos de tempo entre aulas. Entretanto, o jogo pode e deve fazer parte das atividades curriculares, sobretudo nos níveis pré-escolar e de $1^{\circ}$ grau, e ter um tempo preestabelecido durante o planejamento, na sala de aula". (FRIEDMANN, 1996, p.15).
\end{abstract}

Segundo Macedo Et A1, 200:24, “qualquer jogo pode ser utilizado quando o objetivo é propor atividades que favorecem a aquisição do conhecimento. A questão não está no material, mas no modo como ele é explorado pode-se dizer, portanto, que serve qualquer jogo mas não de qualquer jeito". Devem ser utilizados com objetivos educativos, considerando os jogos como facilitadores da aprendizagem na disciplina de matemática.

Nesse momento destaco como importante o pensamento de Kishimoto (2000), que diz: "Para o desenvolvimento do raciocínio lógico matemático, o mediador deve organizar jogos voltados para classificação, seriação, seqüência, espaço, tempo e medidas". A introdução de jogos como recurso didático nas aulas de matemática é tido como facilitador, como um contribuinte, uma vez que os estudantes ainda apresentam medo, receios com relação a disciplina e os jogos acabam diminuindo os bloqueios apresentados pelos estudantes, com relação à matemática, considerando assim o lúdico como ferramenta no aprendizado. 
Não podendo esquecer que, quando se trata de crianças, elas não conseguem ficar concentradas por muito tempo se não estiverem atraídas por algo que está sendo repassado durante as aulas. Sendo assim vale ressaltar o pensamento de Lopes, quando diz,

\begin{abstract}
Um dos pontos importantes para que o professor possa atualizar sua metodologia é perceber que a criança de hoje é extremamente questionadora, não "engole" os conteúdos despejados sobre ela sem saber por que, ou, principalmente para quê. Portanto, o professor deve preocupar-se muito em saber sobre como a criança aprende do que como ensinar. (LOPES, 2001, p: 22).
\end{abstract}

Neste sentido entende-se que o professor deve ser criativo, buscar e adequar as melhores formas de transmitir determinado conteúdo para o seu aluno. E o jogo é e pode servir de ferramenta fundamental na metodologia utilizada pelo professor, no ensino da matemática quando trabalhado de forma lúdica. As autoras Smole, Diniz e Cândido (2007), do livro Cadernos do Mathema Jogos de matemática de $1^{\circ}$ ao $5^{\circ}$ ano, apresentam jogos que contribuem para o ensino de matemática nos primeiros anos, eis aqui alguns deles: Jogo "A Maior Vence", Este jogo: Auxilia os alunos a justificar as respostas e o processo de resolução de um problema, a comparar quantidades, a ler e interpretar escritas numéricas, tendo com recursos um jogo de 40 cartas numeradas de 11 a 50. Onde as crianças poderão utilizar diferentes critérios para comparação dos números, como, por exemplo, pela posição que um número ocupa na sequência numérica, pela identificação de qual dos números tem mais unidades, dezenas ou centenas, ou mesmo pela análise do primeiro algarismo de cada número apresentado nos cartões. (SMOLE, DINIZ e CÂNDIDO, 2007, p. 25). Outro jogo é "Borboleta" jogo este que pode ser usado para que: aprendam a fazer cálculo mental; resolver problemas envolvendo a adição; fazer comparações de quantidades, tendo como recursos todas as cartas do baralho, exceto reis, damas e valetes. (SMOLE, DINIZ E CÂNDIDO (2007, p.55), Cita também o jogo " Um Exato" este jogo auxilia: a reconhecer e nomear números naturais; a justificar respostas; a efetuar adições e subtrações mentalmente com auxilio de: um quadro da centena numerado, três dados e 15 marcadores diferentes para cada jogador. (SMOLE, DINIZ E CÂNDIDO, 2070, p.43), Cita também o Jogo " FAÇA 10", que favorece: a compreensão da contagem; noções de adição; e o cálculo mental, nesse jogo será usado 36 cartas de um baralho normal, sem os 10, as figuras e os coringas (cartas de ás a 9 de todos os naipes). (SMOLE, DINIZ E CÂNDIDO, 2007, p.29). dentre outros, que citam no texto e que contribuem de forma positiva para o processo de alfabetização matemática no ensino infantil e fundamental I.

Friedmann (1996), fala a respeito do jogo como facilitador no aprendizado das crianças: 
O jogo não é somente um divertimento ou uma recreação. Não é necessário provar que os jogos em grupo, é uma atividade natural e que satisfazem á atividade humana; o que é necessário é justificar seu uso dentro da sala de aula. As crianças muitas vezes aprendem mais por meio dos jogos em grupo do que de lições e exercícios. (p.35).

De nada adiantará se elas não se sentirem atraídas pelo que está sendo transmitido pela forma como está sendo feita, se a forma tradicional com lições e exercícios não funcionarem, cabe ao educador procurar as melhores formas e maneiras de fazer essa transmissão, sendo ela de forma lúdica e contextualizada, visando a realidade dos próprios estudantes, dar significado ao que está sendo trabalhado para então repassar aos mesmos.

Friedmann, destaca ainda que,

No jogo, a criança pode experimentar tanto nas convenções estipuladas pela sociedade como as variações dessas convenções. Assim, durante o jogo a criança pode escolher entre aceitar ou discordar de certas convenções, promovendo seu desenvolvimento social. O jogo oferece, muitas vezes, a possibilidade de aprender sobre solução de conflitos, negociação, lealdade e estratégias, tanto de cooperação como de competição social. (FRIEDMANN, 1996, p.65)

Como educadores matemáticos, devemos procurar alternativas para melhorar o ensino e motivar os estudantes para que possam aprender a matemática, como nas palavras de Oliveira, (2007, p. 5),

\begin{abstract}
Ensinar Matemática é desenvolver o raciocínio lógico, estimular o pensamento independente, a criatividade e a capacidade de resolver problemas. Nós como educadores matemáticos, devemos procurar alternativas para aumentar a motivação para a aprendizagem, desenvolver a autoconfiança, a organização, a concentração, estimulando a socialização e aumentando as interações do indivíduo com outras pessoas. (OLIVEIRA, 2007, p. 5).
\end{abstract}

A importância de se trabalhar inserindo os jogos, além de está melhorando suas aulas, tornando-a mais agradáveis, outros pontos importantes em seus estudantes também poderá ser observado, como na afirmação de Fortuna, 2002:21,

Através dos jogos podemos descobrir a personalidade da criança pois ela demonstra o que sente e que tipo de temperamento que possui: tímida, inquieta, agressiva, alegre, calma, temperamental, líder, egoísta, teimosa, intrometida, nervosa, etc. Podemos canalizar os temperamentos e modificar o comportamento das crianças enquanto são ainda pequenas, mais tarde podem surgir problemas de ordem psíquica difíceis de serem controlados. Por isso, a importância da recreação do mundo infantil. Elas aprendem aceitar os outros, controlar suas emoções, expandir seus sentimentos, criar novas situações e a conviver em grupos respeitando a individualidade de cada um." (FORTUNA, 2002:21) 
Aulas atrativas chamam atenção e incentiva o interesse dos estudantes pelas aulas de matemática, quando é colocado o jogo com o objetivo de facilitar o ensino da disciplina, o aluno terá mais prazer em estudar, porém essa prática tem que ser bem elaborada, bem trabalhada e dirigida pelo educador, não se deve em nenhum momento trazer um determinado jogo para passar o tempo da criança na escola sem nenhum fundamento e que não acrescente em nada na vida estudantil daquela criança, tem que dar sentido, significado, ter os jogos, a ludicidade como um aliado em suas aulas, deixando-a mais rica e favorável a todos os envolvidos, professor/aluno.

\section{Considerações Finais}

Este artigo buscou reforçar ainda mais a importância de se trabalhar com atividades lúdicas no ensino de matemática, ressaltando suas contribuições tanto para o professor quanto para a criança.

Sabendo que a Matemática é uma ciência que nos acompanha desde cedo. Ainda pequenos aprendemos a contar nossa idade, familiares, memorizar regras de jogos, entre outras coisas, deve ser dado uma atenção especial neste sentido, de forma a não contribuir com o bloqueio dos estudantes para com a disciplina, mas sim proporcionando aulas agradáveis inserindo os jogos lúdicos como ferramenta facilitadora na aprendizagem, beneficiando de maneira positiva para o desenvolvimento intelectual e potencial de cada criança, onde compete ao professor intervir de forma adequada para cada publico e sempre lembrar que o lúdico é um fator determinante na aprendizagem da criança.

O ensino utilizando os meios lúdicos se torna um ambiente gratificante servindo como estímulo para o desenvolvimento integral da criança que começarão a sentir as aulas mais agradáveis e prazerosas, pois com esse pensamento lúdico, pretende-se melhorar a auto estima, o aprendizado, o interesse pela as aulas, o raciocínio e uma vontade de aprender matemática de uma forma diferenciada, divertida. Mas com objetivos pedagógicos voltados para a alfabetização matemática na vida estudantil das crianças.

E que ao participarem dessas aulas diferentes, prazerosas, distanciem de seus pensamentos a idéia de que matemática é difícil, complicada, cheias de regras e cálculos. No decorrer do trabalho fica claro que os jogos é um recurso pedagógico eficaz se forem bem 
articulados e planejados pelo professor, contribuindo assim para a construção do conhecimento matemático da criança, agindo como um contribuinte no processo de alfabetização matemática.

Durante o trabalho foi colocado uma definição do termo Lúdico, quando se refere a brincadeiras, a momentos de diversão, onde estão incluídos os jogos, brinquedos e, brincadeira, como sendo um aliado e por está auxiliando nas aulas de matemática, teve destaque também a importância do lúdico no ensino de matemática, principalmente nas series iniciais e suas contribuições no auxilio das aulas de matemática bem como distanciar dos estudantes o bloqueio que sentem pela disciplina.

Diante do que foi exposto deixa claro a importância de se trabalhar a disciplina de matemática nas séries iniciais (infantil e fundamental I) com o auxilio do lúdico que serve de ferramenta facilitadora na compreensão dos estudantes na disciplina em questão, colocando em pratica durante as aulas e reconhecer o quanto o lúdico, os jogos podem enriquecer ainda mais as suas aulas, e em especial as aulas de matemática, distanciando os bloqueios adquiridos a muito tempo atrás, com relação a matemática, deixando claro ao professor, que ele sempre deverá buscar inovar e renovar sua metodologia em sala de aula, usando a criatividade, buscando as melhores formas para facilitar no processo de ensino-aprendizagem da matemática pela criança.

\section{Referências}

BRITO, M. R. F. (org.). Psicologia da educação matemática: teoria e pesquisa. Florianópolis: Insular, 2001.

CORBALÁN, F. Juegos matemáticos para secundaria y bachillerato. Madrid: Sintesis, 1994

CUNHA, Nylse Helena da Silva. Brinquedo, desafio e descoberta para utilização e confecção de brinquedos. Rio de Janeiro: Fae, 1988.

DANTAS, Carine Costa; RAIS, Isabela; JUY, Noeli. Jogos e Aprendizagem de Noções Matemáticas na educação Infantil. 2012. 42f. Universidade São Marcos, São Paulo.

EDUCA BRASIL. Disponível em <http://www.educabrasil.com.br/ludico/>. Acesso em 2017. FORTUNA, Tânia Ramos. Papel de brincar. Aspectos relevante a considerar no trabalho lúdico. REVISTA DO PROFESSOR. Porto Alegre, 9.14 Julho/Set 2002. 
FRIEDMANN, Adriana. Brincar: Crescer e aprender: O resgate do jogo infantil. São Paulo: Moderna, 1996.

HALABAN, Sérgio; ZATZ, André e ZATZ, Sílva. Brinca Comigo! Editora Marco Zero: 2006.

KISHIMOTO, Tizuco Morchida. Jogo, brinquedo, brincadeiras e a educação. $4^{\mathrm{a}}$ Ed. São Paulo, Editora Cortez: 2000.

MACEDO, L. de Aprender com jogos e situações-problemas. Porto Alegre: Artes médicas Sul, 2000.

MENEZES, Ebenezer Takuno de; SANTOS, Thais Helena dos. Verbete lúdico. Dicionário Interativo da Educação Brasileira - Educabrasil. São Paulo: Midiamix, 2001. Disponível em: <http://www.educabrasil.com.br/ludico/>. Acesso em: 26 de out. 2017.

MIRANDA, Simão de. Do fascínio do jogo á alegria do aprender nas séries iniciais. São Paulo: Papirus, 2001.

REGO, Teresa Cristina. Vygotsky: uma perspectiva histórico-cultural da educação. $3^{\mathrm{a}}$ ed. Petrópolis: Vozes, 2000

SANTOS, Santa Marli Pires dos. Brinquedoteca: A Criança, o adulto e o lúdico. (org) Petrópolis, RJ: Vozes, 2000.

SMOLE, K.S.; DINIZ, M.I.; CÂNDIDO, P. Cadernos do Mathema: Jogos de Matemática de $\mathbf{1}^{\circ}$ ao 5'. Porto Alegre RS, Artmed Editora S.A.2007.

Como citar este artigo (Formato ABNT):

SILVA, Luciana Verêda da; ANGELIM, Clenilson P. O Lúdico como Ferramenta no Ensino da Matemática. Id on Line Revista Multidisciplinar e de Psicologia, 2017, vol.11, n.38, p. 897--909. ISSN: 1981-1179.

Recebido: 11.11.2017

Aceito: 13.11.2017 